\title{
SISTEM PAKAR DIAGNOSA GEJALA KECANDUAN GAMEONLINE BERBASIS WEB MENGGUNAKAN METODE BACKWARD CHAINING
}

\author{
Shannon Marget Cloudy Silalahi \\ Universitas Bina Nusantara, Jakarta, Indonesia \\ e-mail: shannonmargetcloudy@gmail.com
}

\begin{abstract}
Abstrak
Sistem Pakar adalah bagian dari Kecerdasan Buatan yang mengandung pengetahuan dan pengalaman yang disediakan oleh banyak pakar sesuai wilayah pengetahuan tertentu sehingga setiap orang dapat menggunakan untuk memecahkan masalah yang spesifik. Implementasi sistem pakar banyak digunakan dalam bidang kesehatan seperti gangguan kejiwaan (psikologis) seperti kecanduan atau ketagihan. Sebagai contoh melakukan diagnosa terhadap suatu pertanda kecanduan. Diagnosa adalah proses melakukan pemeriksaan terhadap sesuatu dengan menggunakan cara dan teknik tertentu. Diagnosa dilakukan untuk menjelaskan apakah seseorang mengeluarkan / melaporkan hal tertentu misalnya penyakit psikis seperti kecanduan game online Diharapkan dengan sistem ini, orang awam dapat menyelesaikan masalah tertentu dengan mudah membantu para ahli dalam bidang tersebut. Dan juga memberikan kemudahan dalam mendiagnosa seseorang terhadap kecanduan game online serta memberikan kemudahan dalam informasi kategori terhadap kecanduan game online. Sementara bagi para ahli, sistem ini dapat digunakan sebagai asisten yang berpengalaman. Aplikasi yang dikembangkan ini bertujuan untuk memprediksi tingkat pertumbuhan penduduk dengan hanya menganalisa data tersebut dengan berbasis website. Metode ini merupakan metode yang tepat dalam sistem pakar.
\end{abstract}

Kata Kunci: sistem pakar, diagnosa, game online, berbasis web

\section{WEB BASED EXPERT SYSTEM FOR DIAGNOSTIC SYMPTOMS OF ONLINE GAME ADDICTION USING BACKWARD CHAINING METHOD}

\begin{abstract}
Expert Systems are part of Artificial Intelligence, which contains the knowledge and experience provided by many experts according to certain areas of knowledge so that everyone can use to solve specific problems. The implementation of expert systems is widely used in the field of health such as psychological disorders such as addiction or addiction. For example, diagnosing a sign of addiction. Diagnosis is the process of examining something using certain methods and techniques. Diagnosis is done to explain whether someone issues / reports certain things such as psychological illness such as online game addiction It is expected that with this system, lay people can solve certain problems easily help experts in that field. Also provides convenience in diagnosing someone against online game addiction and provides convenience in the category information on online game addiction. While for experts, we can also use this system as an experienced assistant. This developed application aims to predict population growth rates by only analyzing the data with website-based. This method is the right method in the expert system.
\end{abstract}

Keywords: expert system, diagnosing, online game, web-based. 


\section{Pendahuluan}

Perkembangan teknologi informasi di jaman ini berkembang dengan sangat pesat. Peran komputer kini pun menjadi lebih meluas, tidak hanya menjadi alat bantu hitung seperti penggunaan awal komputer tapi juga menjadi alat bantu penyelesaian masalah-masalah yang dihadapimanusia [1]. Salah satu kemajuan teknologi komputer adalah menyimpan kemampuan seseorang yang berpengalaman di bidangnya ke dalam perangkat lunak dan dapat digunakan untuk pembelajaran dan konsultasi. Inilah yang disebut dengan sistempakar (expert system) yang merupakan salah satu sub bidang ilmu kecerdasan buatan (artificial intelligent) [2].

Bidang kecerdasan buatan yang penulis tertarik untuk mengkaji adalah sistem pakar (expert system). Dimana sistempakar telah banyak diaplikasikan dalamberbagai bidang seperti Teknik, kedokteran, bisnis, ilmu pengetahuan, sosial. Tujuan pengembangan sistem pakarsebenarnya bukanlah untuk menggantikan peran manusia, tetapi untuk menerapkanpengetahuan manusia ke dalam bentuk sistemsehingga dapat digunakan oleh banyak orang. Seperti saat ini game online sedang marak dimasyarakat, peminatnya mulai darianak-anak sampai orang dewasa. Dalammemainkannya terkadang seseorang tidakmengenal waktu sehingga sering kali lupa akan waktu, misalnya saja jam 4 pagi itusewajarnya dipakai orang untuk beristirahat, tapi ternyata tidak untuk sebagian komunitasyang dalam hal ini sebagai gamers, malah digunakan untuk bermain game. Kecanduan game online adalah kesenangan saat bermain game karena memberi rasa kepuasan tersendiri, sehingga perasaan untuk mengulang lagi kegiatan menyenangkan yang ditawarkan ketikabermain game online [3].

\section{Landasan Teori}

\section{Pengertian Sistem Pakar}

Menurut Nira Merlina dan Rahmat Hidayat dalam bukunya Perancangan Sistem Pakar [4], beberapa definisi sistem pakar menurut beberapa ahli yaitu sebagai berikut:

- Menurut Durkin: sistem pakar adalah suatu program yang dirancang untuk memodelkan kemampuan penyelesaian masalah yang dilakukan seorang pakar.

- Menurut Ignizio: sistem pakar adalah suatu model dan prosedur yang berkaitan, dalam suatu domain tertentu yang mana tingkat keahliannya dapat dibandingkan dengan keahlian seorang pakar.

Berdasarkan berbagai pengertian di atas, dapat disimpulkan bahwa sistem pakar merupakan suatu sistem yang menjadikan komputer seolah-olah seperti seorang pakar sehingga dapat memberikan solusi yang berkualitas.

\section{Game online}

Menurut Pratiwi [5], Game online merupakan permainan (games) yang dapat diakses oleh banyak pemain, dimana mesin-mesin yang digunakan pemain dihubungkan oleh suatu jaringan.

Menurut Adams [6], Game online merupakan permainan yang dapat dimainkan oleh multi pemain melalui internet. Game online tidak hanya memberikan hiburan tetapi juga memberikan tantangan yang menarik untuk diselesaikan sehingga individu bermain game online tanpa memperhitungkan waktu demi mencapai kepuasan. Hal ini menjadikan gamer tidak hanya menjadi pengguna game online tetapi juga dapat menjadi pecandu game online.

\section{Metode Penelitian}

Sebelum merancang aplikasi, terdapat beberapa hal yang dijadikan landasan dalam proses penggalian pengetahuan terhadap pecandu game online. Jenis perilaku kecanduan game online terbagi menjadi tiga 
tingkatan yaitu Rendah, Sedang, dan Tinggi. Adapun list pertanyaan di bawah ini yang penulis gunakan dalam merancang form input dari diagnosa gejala kecanduan game online yang diperoleh dari wawancara terhadap pakar.

Tabel 1 Gejala Kecanduan Game online

\begin{tabular}{|l|l|l|}
\hline \multicolumn{1}{|c|}{$\begin{array}{c}\text { Kode } \\
\text { Gejala }\end{array}$} & $\begin{array}{c}\text { Kode } \\
\text { Jenis }\end{array}$ & \multicolumn{1}{c|}{ Gejala Kecanduan Game online } \\
\hline G1 & JKGO1 & $\begin{array}{l}\text { Ketika bermain game, apakah anda mempedulikan kebutuhan } \\
\text { sendiri, misalnya makan? }\end{array}$ \\
\hline G2 & JKGO1 & $\begin{array}{l}\text { Apakah bermain game online menghibur Anda dari kegiatan belajar } \\
\text { atau bekerja? }\end{array}$ \\
\hline G3 & JKGO1 & Apakah Anda merasa senang bermain game online? \\
\hline G4 & JKGO2 & Apakah Anda merasa cemas jika tidak bermain game online? \\
\hline G5 & JKGO2 & $\begin{array}{l}\text { Apakah Anda pernah gagal dalam usaha untuk berhenti bermain } \\
\text { game online? }\end{array}$ \\
\hline G6 & JKGO2 & Apakah waktu bermain game online Anda setiap hari bertambah? \\
\hline G7 & JKGO2 & Apakah Anda senang bila memenangkan permainan game online? \\
\hline G8 & JKGO3 & $\begin{array}{l}\text { Apakah anda memikirkan permainan game online saat Anda sedang } \\
\text { tidak bermain game online? }\end{array}$ \\
\hline G9 & JKGO3 & $\begin{array}{l}\text { Apakah anda merasa terikat dengan game online? (mengharapkan } \\
\text { sesi bermain game selanjutnya) }\end{array}$ \\
\hline G10 & JKGO3 & $\begin{array}{l}\text { Apakah jumlah waktu Anda bermain game online mempengaruhi } \\
\text { tingkat kepuasan anda dalam bermain game online? }\end{array}$ \\
\hline G11 & JKGO3 & $\begin{array}{l}\text { Apakah hubungan sosial Anda berkurang karena kebiasaan bermain } \\
\text { game online? }\end{array}$ \\
\hline G12 & JKGO3 & $\begin{array}{l}\text { Apakah Anda merasa terancam kehilangan kesempatan Pendidikan } \\
\text { atau pekerjaan karena kebiasaan bermain game online? }\end{array}$ \\
\hline
\end{tabular}

Dalam penanganan dari gejala kecanduan game online, penulis membagi solusi terhadap masingmasing tingkatan dari kecanduan game online. Dimulai dari tingkatan rendah yang belum membutuhkan bantuan orang lain dalam mengontrol perilaku, hingga ke tingkat tinggi yang membutuhkan perhatian dari orang tua atau pengawas di lingkungan pecandu game online yang terdiagnosa.

Tabel 2 Solusi Berdasarkan Jenis Kecanduan Game online

\begin{tabular}{|c|c|}
\hline Jenis Kecanduan Game online & Solusi \\
\hline Rendah (Mild) & Mengurangi waktu bermain dengan pemain game online. \\
\hline Sedang (Moderate) & $\begin{array}{l}\text { Mengisi waktu dengan hal yang bermanfaat seperti berolahraga, } \\
\text { membaca buku, atau kegiatan sosial lain, guna mengalihkan pikiran dari } \\
\text { game online. }\end{array}$ \\
\hline Tinggi / Parah (Severe) & $\begin{array}{l}\text { Untuk Orang Tua: } \\
\text { 1. Sediakan lebih banyak waktu Bersama dengan anak. } \\
2 . \quad \text { Mengembangkan cara berkomunikasi yang lebih baik dengan } \\
\text { anak. } \\
\text { 3. Rencanakan waktu untuk makan Bersama, rekreasi, atau } \\
\text { jalan-jalan guna menciptakan suasana yang nyaman. } \\
4 . \quad \text { Jangan berbicara kasar atau marah-marah kepada anak } \\
\text { ketika bermain game online. } \\
\text { Untuk Gamer. } \\
\text { 1. Menanamkan niat untuk mengatasi kecanduan game, seperti } \\
\text { membuat komitmen dengan niat untuk menghilangkan kecanduan } \\
\text { dalam bermain game. } \\
2 . \quad \text { Hitung kembali biaya yang sudah Anda keluarkan dan } \\
\text { sadarkan diri Anda jika biaya tersebut dikumpulkan akan memiliki } \\
\text { fungsi yang lebih baik dan lebih berguna. } \\
3 . \quad \text { Cobalah mencari hobi yang baru. } \\
4 . \quad \text { Perbanyak aktivitas sosial. } \\
5 . \quad \text { Menceritakan tentang kecanduan game online yang Anda } \\
\text { alami agar orang terdekat bisa memberi dukungan dan jalan keluar } \\
\text { untuk Anda serta dapat menjadi pengingat. }\end{array}$ \\
\hline
\end{tabular}




\section{Production Rules}

Production rules adalah salah satu aturan yang dapat digunakan untuk melakukan penalaran atau penelusuran basis pengetahuan awal sehingga menghasilkan knowledge base yang berguna untuk mencapai tujuan [7]. Berdasarkan data yang ditunjukkan pada Tabel 3.1 Jenis Perilaku Kecanduan Game online dan Tabel 3.2 Gejala Kecanduan Game online, maka rule model menghasilkan tiga rule. Dimulai dari $\mathrm{R} 1$ sampai dengan R3, menggunakan pemodelan backward chaining [8] dengan aturan-aturan sebagai berikut:

Rule Model Backward Chaining Diagnosa Gejala Kecanduan Game online

R1: IFG1 or G2 THEN

JKGO1

R2: $\quad$ IFG3 or $\mathrm{G} 4$ or $\mathrm{G} 5$ or $\mathrm{G} 6$ or $\mathrm{G} 7$ THEN

JKGO2

R3: $\quad$ IFG8 or $\mathrm{G} 9$ or $\mathrm{G} 10$ or $\mathrm{G} 11$ or $\mathrm{G} 12$ THEN

JKGO3

R4: IF COUNT(RI : R3) > 3 THEN

KECANDUAN GAME ONLINE

\section{Unified Modelling Language}

Dalam membantu penulis dalam merancang aplikasi, penulis menggunakan Unified Modelling Language (UML) seperti use case diagram dan activity diagram untuk menjelaskan peran dan alur dalam aplikasi [9]. Adapun Use case diagram yang digunakan dapat dilihat di Gambar 1.

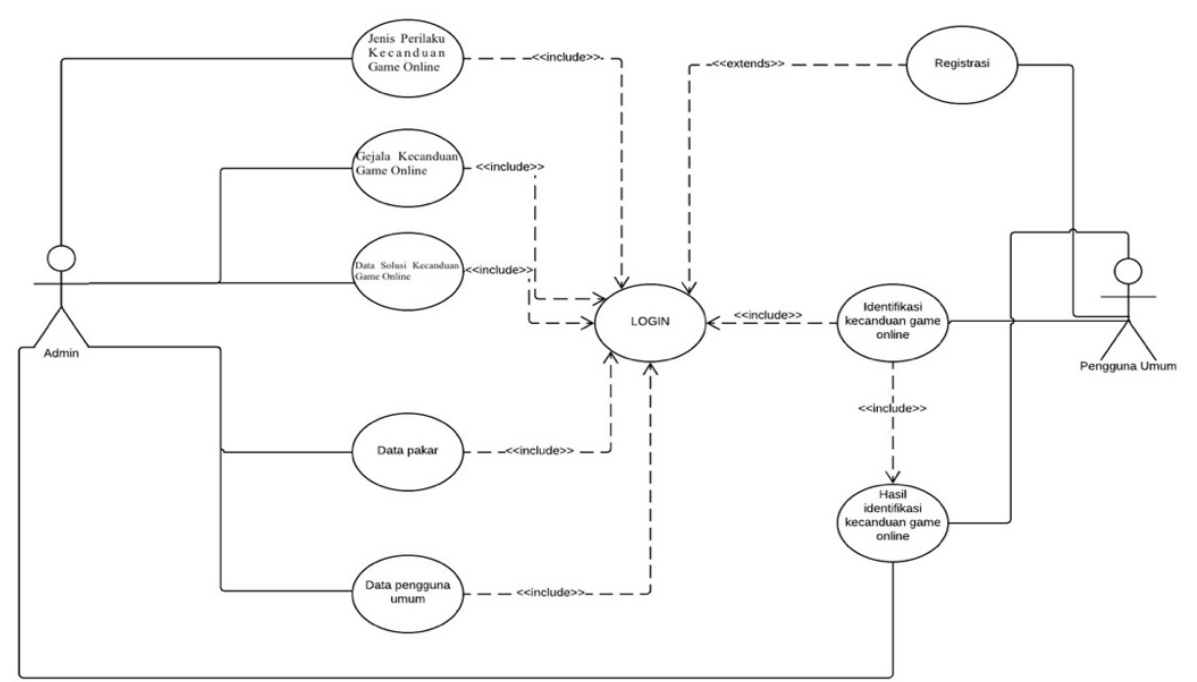

Gambar 1 Use case diagram Aplikasi 
Dan untuk dapat memahami lebih lanjut mengenai aktivitas yang terjadi dalam aplikasi, penulis menggunakan Activity diagram yang terbagi ke dalam 3 buah diagram. Pertama, Activity diagram Login yang menggambarkan bahwa pengguna perlu untuk mendaftarkan akun lalu kemudian masuk ke dalam aplikasi melalui form login yang disediakan. User meng-input username dan password dan form login akan diproses oleh sistem dengan me-load data user dan mencocokkan data dengan username dan password yang sudah tersimpan di dalam database, jika prosesnya salah maka akan muncul pesan invalid login, sebaliknya jika prosesnya benar maka userakan masuk ke form menu utama. Aktivitas ini tergambar dalam Gambar 2 di bawah ini.

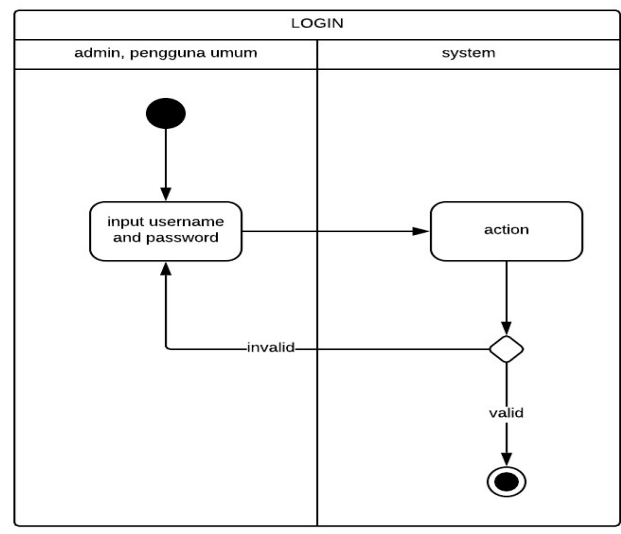

Gambar 2 Activity diagram Login

Kedua, Activity diagram Input Gejala Diagnosa dimana Actor akan meng-input data kriteria diagnosa gejala kecanduan game online yang akan divalidasi oleh sistem dan akan di cek oleh pakar, jika data tersebut invalid maka akan error, sebaliknya jika data tersebut valid makan akan sukses untuk meng-input data kriteria diagnosa gejala kecanduan game online. Aktivitas ini tergambar dalam Gambar 3 di bawah ini.

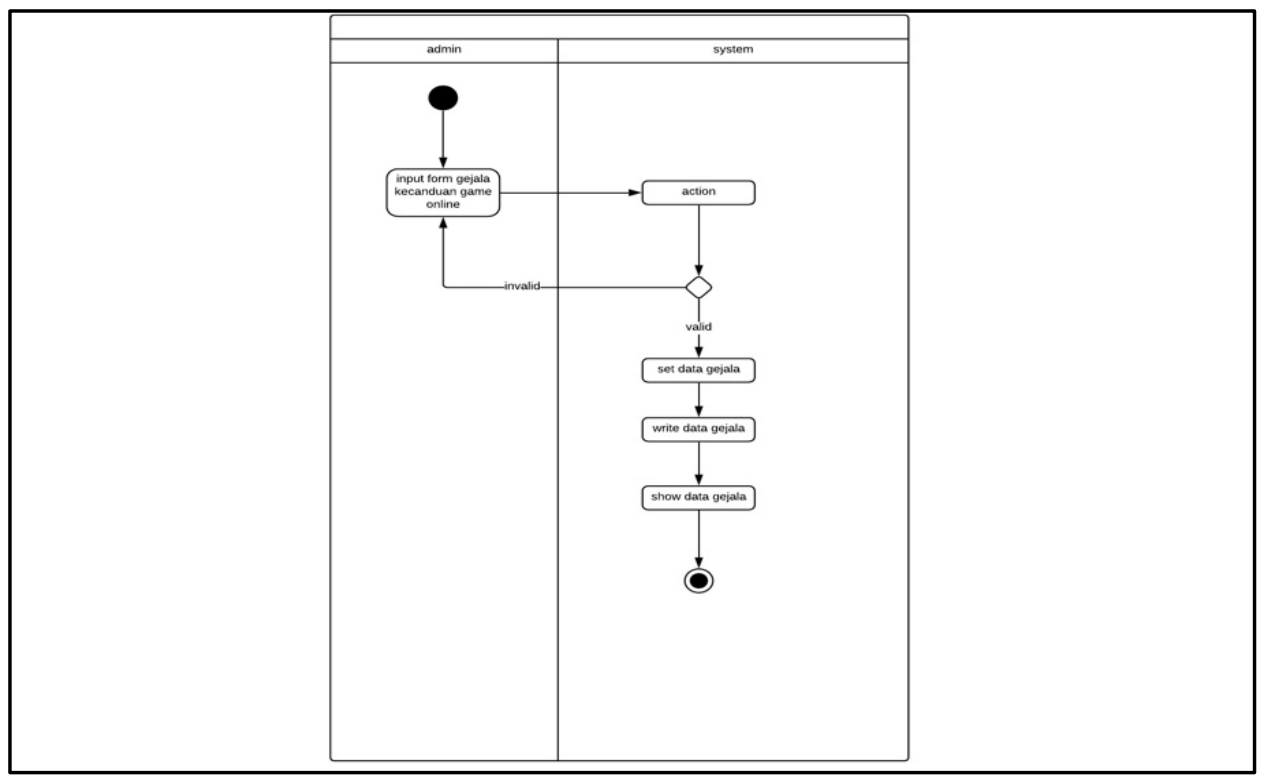

Gambar 3 Activity diagram Input Gejala Diagnosa

Ketiga, Activity diagram Update Gejala Diagnosa yang dioperasikan oleh admin. Dimana Admin mempunya hak akses untuk mengelola data seperti create, read, delete, dan update di dalam system. Aktivitas ini tergambar dalam Gambar 4 di bawah ini. 


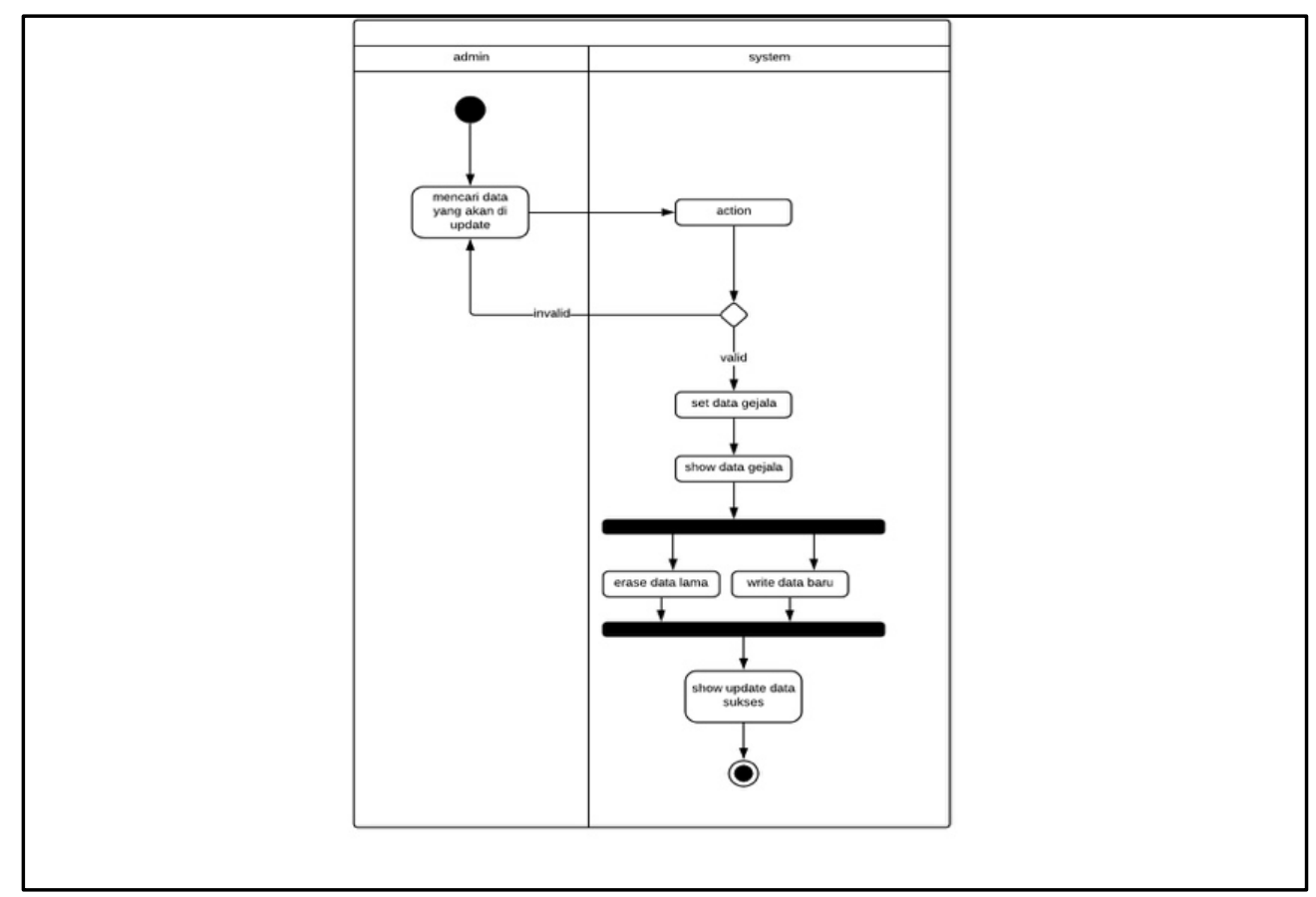

Gambar 4 Activity diagram Update Gejala Diagnosa (Admin)

Penulis menggunakan Class diagram dalam mendeskripsikan jenis-jenis objek yang saling berhubungan di dalam sistem dan menjelaskan batasan yang berhubungan pada sistem untuk membantu pengembangan sistem tersebut [10]. Class diagram sering digunakan sebagai acuan utama pengembangan disebabkan semua kebutuhan perancang terhadap sistem ini melalu tampilan dibantu dengan mempresentasikan fungsi-fungsi yang tertera dari class diagram.

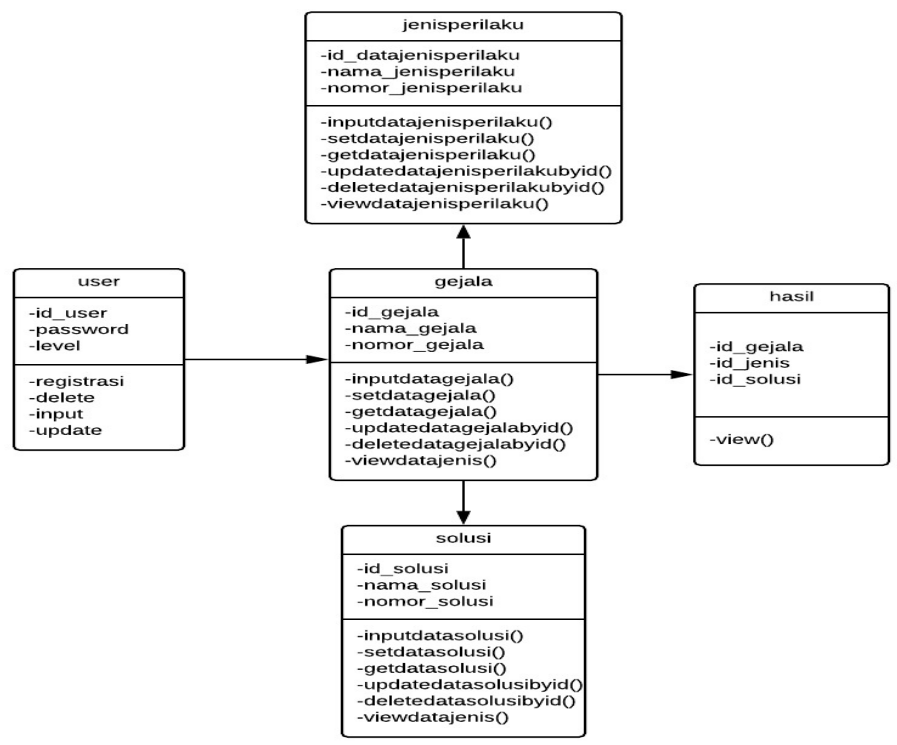

Gambar 5 Class diagram Aplikasi

\section{Hasil}


Dalam merancang aplikasi ini, terdapat perangkat lunak yang penulis gunakan diantaranya XAMPP dan web browser. Sedangkan penulis menggunakan Macbook 12 sebagai perangkat keras untuk merancang aplikasi ini. Tampilan awal dari aplikasi ini adalah tampilan login pengguna umum diminta untuk mengisi username dan password dan level kemudian akan di verifikasi oleh sistem untuk mengizinkan pengguna mengakses sistem sesuai dengan levelnya, jika tidak terverifikasi maka sistem tidak akan mengizinkan pengguna untuk masuk pada tampilan menu utama. Tampilan berikutnya adalah tampilan utama di mana pengguna dapat melakukan diagnosa gejala kecanduan game online.
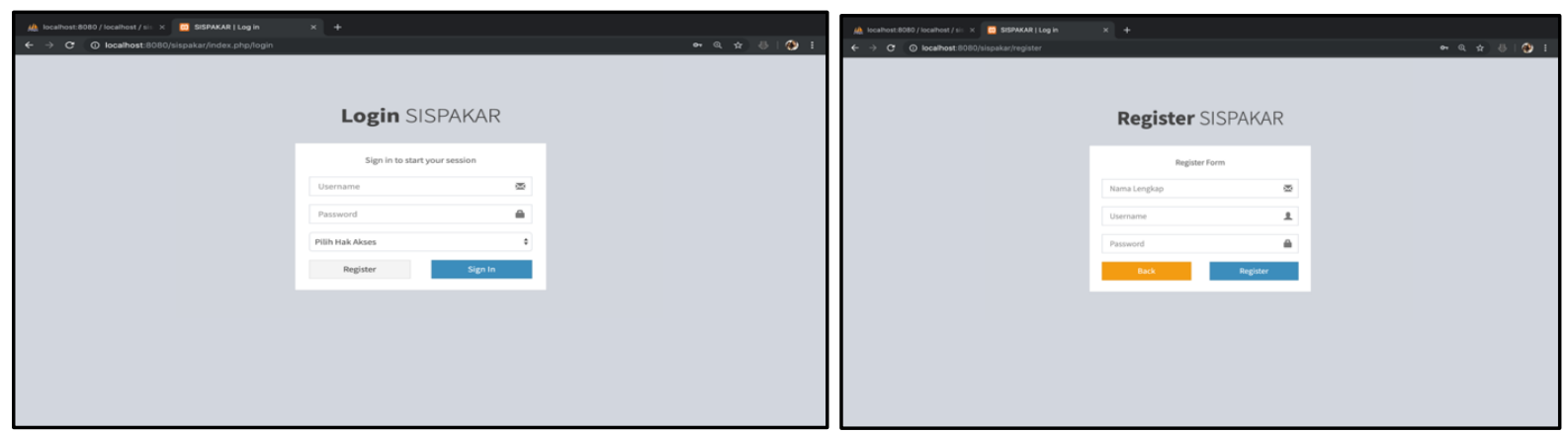

Gambar 6 Tampilan Register dan Login SISPAKAR

Ketika user telah berhasil masuk ke dalam akunnya, maka selanjutnya pengguna akan diarahkan ke halaman utama yang memungkin pengguna untuk dapat memulai diagnosa Ketika menekan tombol Mulai Diagnosa. Sedangkan tombol Pakar hanya dapat diakses oleh Admin untuk dapat merubah data dari diagnosa maupun data useryang sudah terdaftar dalam system.

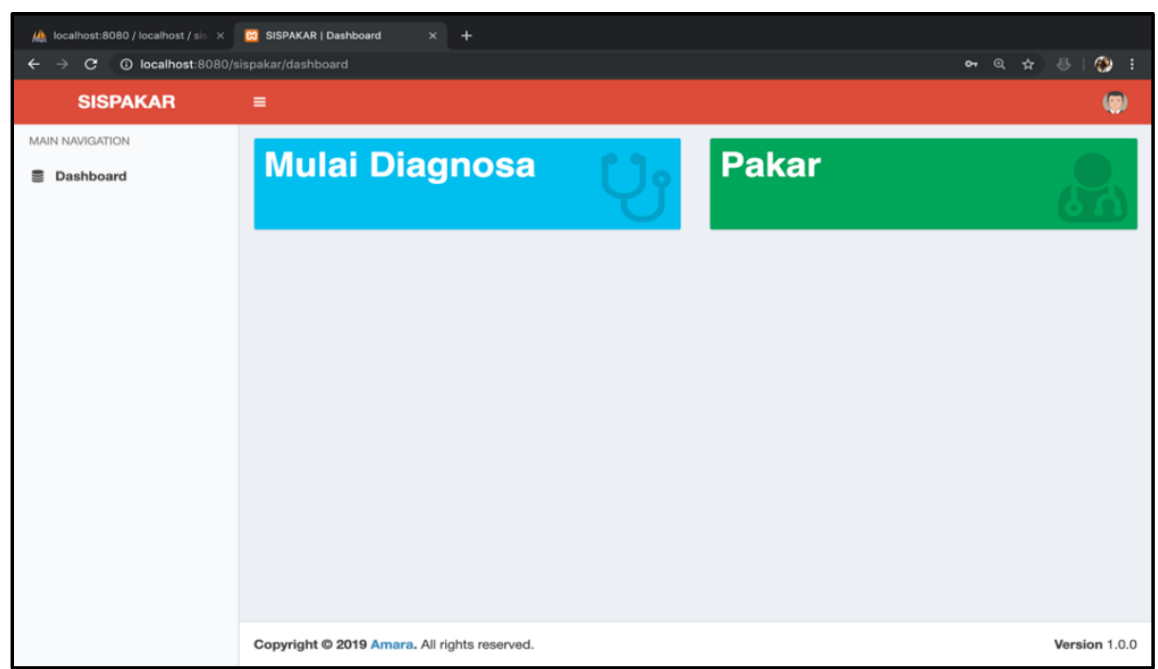

Gambar 7 Halaman Utama SISPAKAR

Form input dari gejala yang mungkin dialami oleh pengguna akan muncul Ketika tombol mulai diagnosa ditekan. Ketika pengguna sudah mengisi seluruh pertanyaan yang ada dalam form tersebut, dan menekan tombol submit. Maka pengguna akan diarahkan ke hasil diagnosa yang menampilkan tingkat kecanduan yang pengguna alami serta solusi terhadap diagnosa tersebut. Form input dapat dilihat di gambar 8, sedangkan hasil diagnosa dapat dilihat di gambar 9 . 


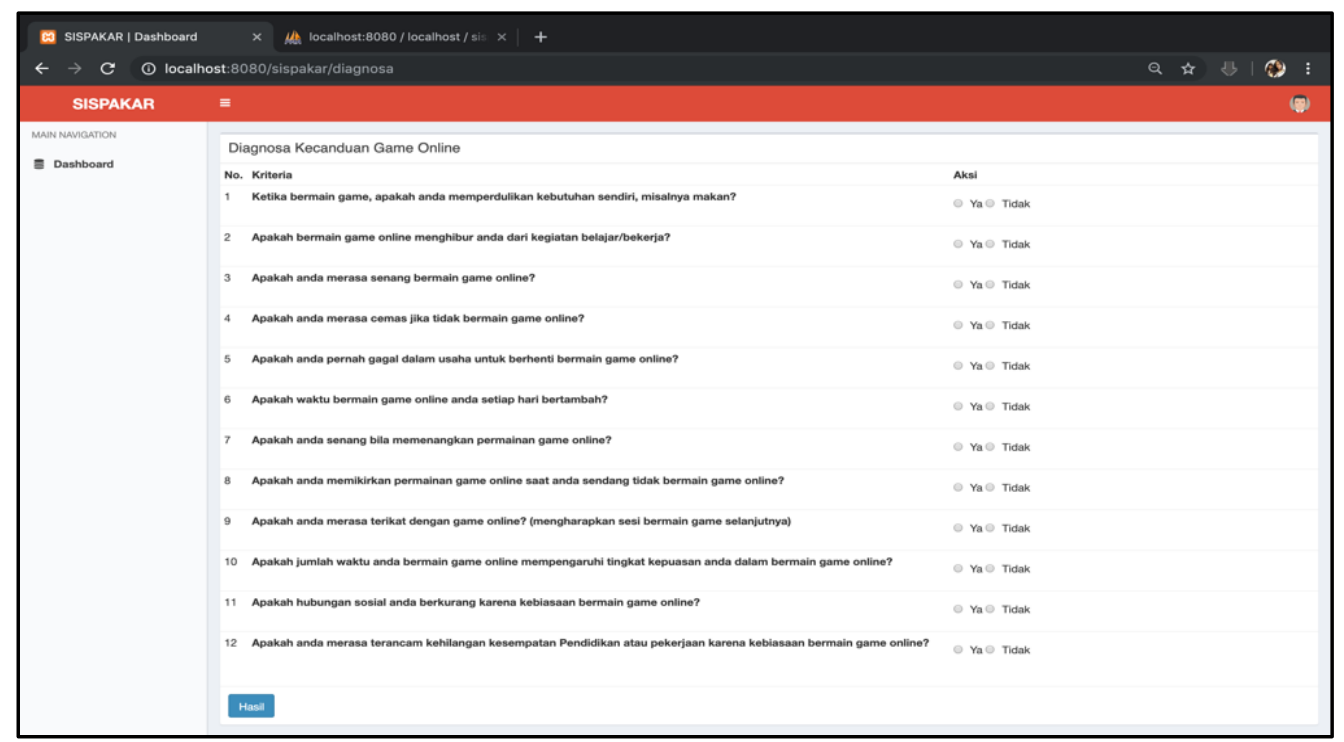

Gambar 8 Form Input Gejala

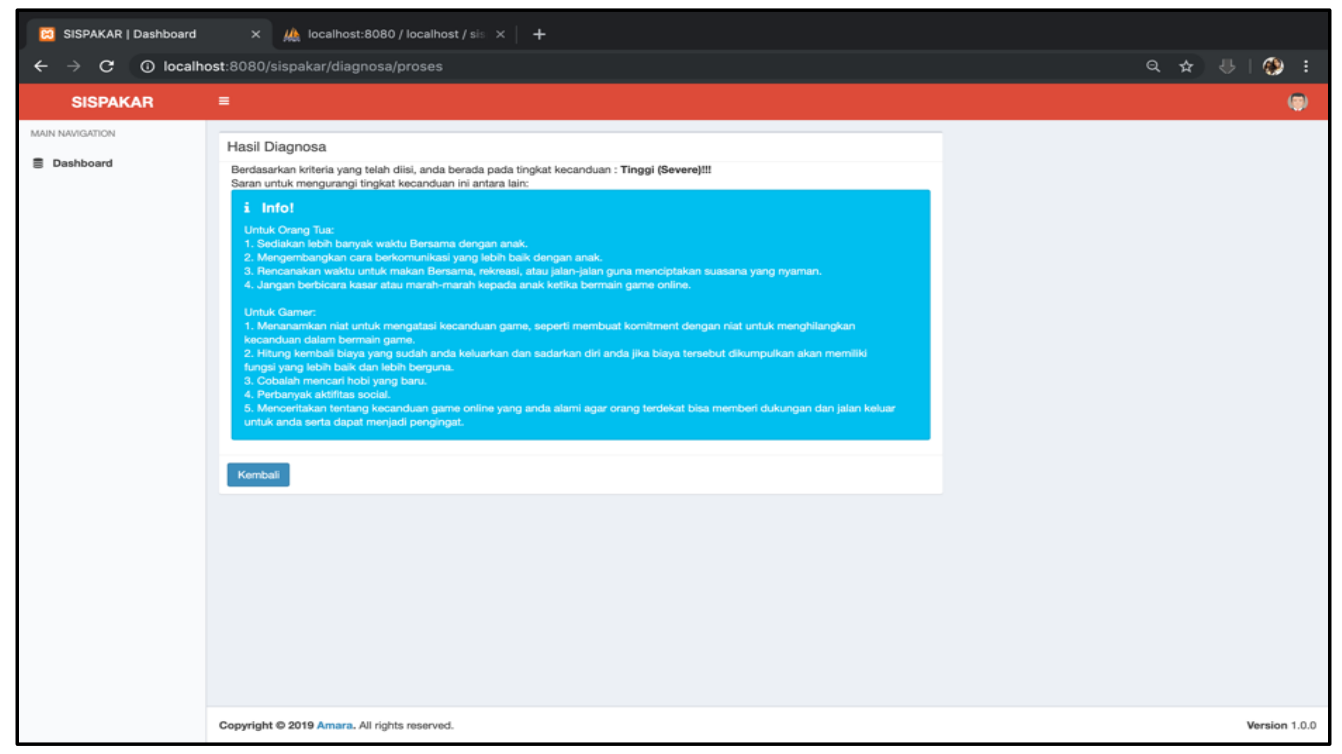

Gambar 9 Hasil Diagnosa dan Solusi

\section{Pembahasan/Kesimpulan}

Setelah menganalisa sistem dan permasalahan yang terjadi pada pemain game online yang mengalami kecanduan, maka dapat disimpulkan bahwa:

1. Aplikasi ini menggunakan metode backward chaining sebagai rules yang menentukan tingkatan diagnosa gejala kecanduan game online.

2. Dengan adanya aplikasi berbasis web ini akan mempermudah masyarakat untuk mendiagnosa apakah mereka kecanduan game online.

3. Aplikasi yang dibuat ini menghasilkan output yang merupakan solusi untuk mengatasi user yang mengalami kecanduan game online. 
Dan Berdasarkan perancangan sistem diagnosa gejala kecanduan game online dan dari kesimpulan yang diperoleh, agar pengembangan sistem pakar ini lebih baik kedepannya. Maka dapat diberikan beberapa saran untuk pengembangan mengenai aplikasi ini selanjutnya, yaitu:

1. Untuk daftar gejala dan rules dapat ditambahkan untuk dapat mendiagnosa dengan lebih spesifik dan dengan menggunakan metode backward chaining.

2. Harapan penulis agar aplikasi ini dapat dikembangkan lagi secaramaksimal agar dapat lebih membantu bukan hanya remaja tetapi juga dewasa yang kecanduan game online.

\section{Referensi}

[1] J. Hartono, Pengenalan Komputer Edisi III, Yogyakarta: Penerbit Andi, 2002.

[2] T. Sutojo, Kecerdasan Buatan, Yogyakarta: Penerbit Andi, 2011.

[3] N. P. Dewi and Taufik, "Hubungan Antara Intensitas Bermain Game online Dengan Interaksi Sosial Pada Remaja," UNIVERSITAS MUHAMMADIYAH SURAKARTA, Yogyakarta, 2014.

[4] N. Merlina and R. Hidayat, Perancangan Sistem Pakar, Ghalia Indonesia, 2012.

[5] P. Christy Pratiwi, T. R. Andayani and N. A. Karyanta, "Perilaku Adiksi Game-online Ditinjau dari Efikasi Diri Akademik dan Keterampilan Sosial pada Remaja di Surakarta," Jurnal Ilmiah Psikologi Candrajiwa, vol. 1, no. 2, 2012.

[6] E. Adams, Fundamentals of Game Design 2nd Edition, Barkeley, CA: New Riders, 2009.

[7] U. Abdullah, A. Ahmed, S. Asghar and K. Zafar, "Record-Couple Based Production Rule Mining Algorithm: Tested in Medical Billing Domain," Journal of Applied Environmental and Biological Sciences, vol. 4, pp. 275-280, 2014.

[8] J. E. Hutagalung and J. Hutahaean, "Sistem Pakar Dengan Metode Backward Chaining Untuk Pengujian Transistor Di Laboratorium Elektronika," Riau Journal of KomputerScience, vol. 1, no. 1, pp. 9-15, 2015.

[9] Haviluddin, "Memahami Penggunaan UML (Unified Modelling Language)," Jurnal Informatika Mulawarman, vol. 6, no. 1, pp. 1-15, 2011.

[10] Riandy, K. Huliyah and A. Subiyakto, "Rancang Bangun Sistem Informasi Penjualan Barang (Studi Kasus: U.D Cendana Depok Townsquare)," Studi Informatika: Jurnal Sistem Informasi, vol. 4, no. 1, pp. 1-6, 2011. 